\title{
Impact of Peritumoral Edema on Overall Survival in Glioblastoma Multiforme
}

\section{Mustafa KANDAZ, ${ }^{1}$ Ozan Cem GÜLER, ${ }^{1}$ Uğur YAZAR, ${ }^{2}$ Şehbal YEŞiLbAŞ ÜÇÜNCÜ, ${ }^{3}$ Adnan YÖNEY ${ }^{1}$}

'Department of Radiation Oncology, Karadeniz Technical University Faculty of Medicine, Trabzon-Turkey

${ }^{2}$ Department of Brain Surgery, Karadeniz Technical University Faculty of Medicine, Trabzon-Turkey

${ }^{3}$ Department of Public Health, Karadeniz Technical University Faculty of Medicine, Trabzon-Turkey

\begin{abstract}
OBJECTIVE
The aim of the present study was to investigate the relationship between peritumoral edema and overall survival in glioblastoma multiforme (GBM).

\section{METHODS}

Total of 101 patients with radiologically or pathologically GBM were included in this study. Data of patient age, sex, tumor dimensions, and preoperative peritumoral edema were analyzed.

\section{RESULTS}

While average survival was $16.67 \pm 3.99$ months (95\% confidence interval [CI]: 8.85-24.49 months) and 1 - and 3-year survival rates were $50 \%$ and $16.7 \%$, respectively, for patients without edema, average survival was $13.74 \pm 1.95$ months (95\% CI: 9.91-17.58 months) and 1- and 3-year survival rates were $35.6 \%$ and $8.5 \%$, respectively, for patients with edema. No statistical difference between them was found $(\mathrm{p}=0.297)$.
\end{abstract}

\section{CONCLUSION}

Prognostic value of edema for survival could not be determined in this retrospective analysis of homogeneous group of patients with isolated GBM.

Keywords: Glioblastoma multiforme; peritumoral edema; survival.

Copyright $\odot$ 2016, Turkish Society for Radiation Oncology

\section{Introduction}

Although brain tumors are a significant morbidity and mortality reason relatively common in adults, metastatic tumors are seen most frequent in brain.[1] More than half of brain tumors are malign glioms (WHO Grade III-IV) and approximately $3 / 4$ of them are grade IV glioblastoma multiforme (GBM).[2] While it can be seen at every age, it peaks between 45 and 55 years of ages.

GBM's standart treatment is surgical. The main aim of surgical treatment is a complete surgical excision which has a direct relationship with disease-free survival and overall survival.[3,4] However, because GBM has a high local recurrence rate, there is a need for adjuvant therapies after surgical treatment. In the Stupp and his colleagues' joint randomized phase III study with European Organisation for Research and Treatment of Cancer (EORTC)/National Cancer Institute of Canada (NCIC) groups, it is shown that adding temozolomide (TMZ) $\left(75 \mathrm{mg} / \mathrm{m}^{2}\right)$ which is an oral alkylating agent and 5 cures $\left(150-200 \mathrm{mg} / \mathrm{m}^{2}\right)$ of adjuvant therapy simultaneously to the standart conventional radiotherapy (RT) extends the survival significantly compared 
to the RT alone. Nowadays, GBM patients' standart treatment is determined like "complete surgical excision+simultaneous chemoradiotherapy+adjuvant chemotherapy".[5,6]

In high grade tumors age, KPS, histology, resection width, duration of symtomes, neurological-functional mental state and tumor's crossover to the opposite lobe are defined prognostic factors.[7-11] Our intention in this study is to observe peritumoral edemas' effect to the survival in GBM.

\section{Materials and Methods}

101 patients that medical inoperable ones' GBM diagnosis were made by radiologically, operated ones' GBM diagnosis were made by pathologically and RT and simultaneously chemotherapy (CT) were applied and monitored for adjuvant therapy, are included in this study. The patients age, sex, tumor's dimensions and peritumoral edema were recorded.

\section{Treatment}

Computer tomography scans were done for RT applicaton. The mass or mass loge was fusioned with MRG which has had before surgical treatment. Brainstem, lenses, optical nerrves, pituitary gland and optical chiasm were contoured as critical organs.

The 3 dimensional conformal radiotherapy (3DRT) or intensity modulated radiotherapy (IMRT) techniques were used. In RT planning, if there wasn't an edema, the mass or mass bed was described as the GTV2 in terms of gross tumor volume (GTV), if there was an edema, it is described as the GTV1 including that. The clinical tumor volume (CTV) was forged with $2 \mathrm{~cm}$ margins given to the GTV1 or GTV2. The CTV was excluded from anatomic barriers if there was not an extension. The planned target volume (PTV) was forged with $0.5 \mathrm{~cm}$ margins given to the CTV. 2 Gy each for 23 fractions total 46 Gy were given to the PTV1, 2Gy/7 fractions total 14 Gy were given to the PTV2 and grand total tumor dose reached to $60 \mathrm{~Gy}$. Everyday orally $75 \mathrm{mg} / \mathrm{m}^{2} \mathrm{TMZ}$ was applied as simultaneously CT. After RT, once in 28 days, 5 days long $150-200 \mathrm{mg} / \mathrm{m}^{2} \mathrm{TMZ}$ was applied for 5 cures.

\section{Follow-up}

After RT, clinical examination, complete blood test and MRG controls were done with 2 months periods. The overall survival was accepted as the time between diagnosis and last control or death date.

\section{Statistical methods}

The obtained data was loaded to the SPSS 13.0 softwere. The Kaplan-Meier test was used for survival times. The prognostic factors were calculated with the long-rank test. $\mathrm{P}<0.05$ was accepted as significant.

\section{Results}

$39 \%$ (39) of 101 patients that involved to the study were females and $61 \%(62)$ of them were males. The age average was $62.72 \pm 13.56(7-88) .15(15 \%)$ patients were $<50$ years old, $86(85 \%)$ of them $\geq 50$ years old.

The average tumor size was $4.03 \pm 1.46 \mathrm{~cm}(1.5-8.0)$ and at $59(58 \%)$ patients $\leq 4 \mathrm{~cm}$ and at $42(42 \%)$ of them $>4 \mathrm{~cm}$. Because they were medical inoperable at $23(23 \%)$ patients diagnosis was made by radiologically. $23(23 \%)$ of the 78 (77\%) patients who were operated, only biopsy was applied. Subtotal excision was made to $21(21 \%)$ patients and total excision was made to $34(33 \%)$ of them. The drawn volumes at the RT planning; the mass was $92.03 \pm 107.58$ (13.65-721.21) $\mathrm{cm}^{3}$, PTV 0-46 544.88 $\pm 240.19(50.91-1257.85) \mathrm{cm}^{3}$ and PTV 46-60 319.45 $\pm 172.32(19.81-899.96) \mathrm{cm}^{3}$. If it was evaluated based on sex; while the average survival at females was $13.45 \pm 2.13$ (95\% CI: 9.28-17.63) months, and 1 and 3 years survival rates were 33.6\% and $5.7 \%$ respectively, the average survival at males was 13.95 \pm 2.06 (95\% CI: 9.91-17.98) months and 1 and 3 years survival rates were $37.7 \%$ and $9 \%$, and there were no statistically difference between them. If the survival was evaluated based on age; while the average survival was $24.83 \pm 3.01$ (95\% CI: 18.91-30.75) months, 1 and 3 years survival rates were $79 \%$ and $15 \%$ respectively at the patients below 50 years old, the average survival was $11.44 \pm 1.56$ (95\% CI: 8.38-14.50) months, 1 and 3 years survival rates were $28.7 \%$ and $5.6 \%$ respectively and, there was a statistically significant difference between them ( $\mathrm{p}=0.001)$. If the survival was evaluated by tumor size; while at the patients $\leq 4 \mathrm{~cm}$ the average survival was $8.13 \pm 2.24$ (95\% CI: 3.72-12.53) months, 1 and 3 years survival rates were $35.9 \%$ and $14 \%$ respectively, at the patients $>4 \mathrm{~cm}$ survival was $11.49 \pm 1.62$ (95\% CI: 8.32-14.67) months, 1 and 3 years survival rates were $39.5 \%$ and $0 \%$. A significant relation between tumor size and survival couldn't be found $(\mathrm{p}=0.0404)$. While the average survival at the patients who were treated without surgical operation was $9.50 \pm 2.05$ (95\% CI: 5.46-13.53) months, 1 and 3 years survival rates $24.8 \%$ and $0 \%$ respectively, the average survival at the patients who were applied biopsy and subtotal excision was $11.88 \pm 1.62$ (95\% CI: 8.38-14.50) months, 1 and 3 


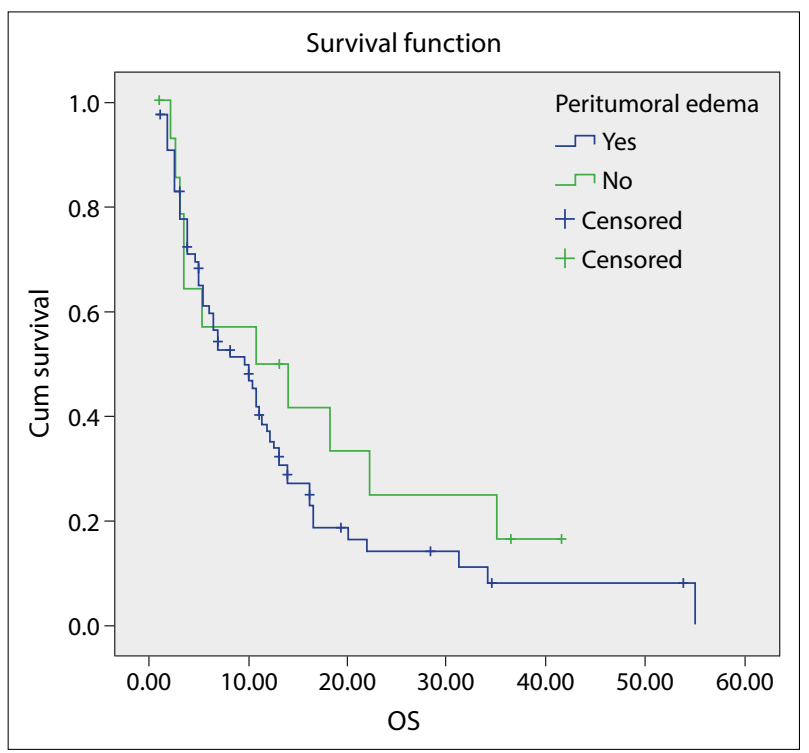

Fig. 1. Overall survival.

years survival rates were $39.1 \%$ and $3.3 \%$ respectively, the average survival at the patients who were applied total excision was $19.62 \pm 3.82$ (95\% CI: 12.13-27.12) months, 1 and 3 years survival rates were $39.3 \%$ and $23.9 \%$ respectively and, a statistically significant relation between them couldn't be found ( $p=0.099)$.

While there was no peritumoral edema at $15(15 \%)$ patients, at $86(85 \%)$ of them there was an edema and the average volume of the edema was $145.71 \pm 133.92$ $(0.0-549.80) \mathrm{cm}^{3}$. If the survival was evaluated for peritumoral edema at the GBM patients; while the average survival was $16.67 \pm 3.99$ (95\% CI: 8.85-24.49) months, 1 and 3 years survival rates were $50 \%$ and $16.7 \%$ respectively at the patients without edema, the average survival was $13.74 \pm 1.95$ (95\% CI: 9.91-17.58) months, 1 and 3 years survival rates were $35.6 \%$ and $8.5 \%$ respectively at the patients with edema and, there wasn't a statistical difference between them $(\mathrm{p}=0.297)$ (Figure 1).

If the peritumoral edema was evaluated for sex; while there was no peritumoral edema at 5 female patients, at 34 of them there was an edema. The edema seen rate at females was $87 \%$. The average survival of female patients without edema was $21.40 \pm 7.32$ (95\% CI: 7.04-35.75) months, 1 and 3 years survival rates were $50 \%$ and $25 \%$, the average survival of female patients with edema was $11.44 \pm 1.91$ (95\% CI: 7.69-15.20) months, 1 and 3 years survival rates were $33.8 \%$ and $0 \%$ respectively. There was no statistical difference between two groups $(\mathrm{p}=0.145)$. While the edema wasn't observed at 10 male patients, at 52 of them it was observed. The edema rate at male patients was $83 \%$. The average survival of male patients without edema was $13.79 \pm 4.18$ (95\% CI: 5.58-22.0) months, 1 and 3 years survival rates were $50 \%$ and $12.5 \%$, the average survival of male patients with edema was $14.42 \pm 2.64$ (95\% CI: 9.23-19.61) months, 1 and 3 years survival rates were $34 \%$ and $10.4 \%$ respectively. There was no statistical difference between two groups $(\mathrm{p}=0.406)$. If all groups compared with each other, there was no statistical difference between them $(p=0.619)$.

If the peritumoral edema was evaluated for age; while there was no peritumoral edema at 4 patients under ages of 50 , at 11 of them there was an edema and, edema seen rate was $73 \%$. The average survival was $26.99 \pm 4.63$ (95\% CI: 17.91-36.07) months, 1 and 3 years survival rates were $75 \%$ and $25 \%$ respectively at the patients under 50 years with no edema. The average survival rate was $23.91 \pm 4.10$ (95\% CI: $15.87-31.96$ ) months, 1 and 3 years survival rates were $70.7 \%$ and $0 \%$ respectively at the patients under 50 years with edema. There was no statistical difference between two groups $(\mathrm{p}=0.800)$. The average survival rate was $12.15 \pm 4.49$ (95\% CI: 3.33-20.96) months, 1 and 3 years survival rates were $30 \%$ and $15 \%$ respectively at the patients 50 years old and over with no edema. The average survival rate was $11.04 \pm 1.53$ (95\% CI: 8.02-14.06) months, 1 and 3 years survival rates were $30.1 \%$ and $4.3 \%$ respectively at the patients 50 years old and over with edema. There was no statistical difference between two groups $(\mathrm{p}=0.918)$. But, if all groups were compared, there was a statistical difference $(\mathrm{p}=0.034)$.

If the peritumoral edema was evaluated for tumor size; while there was no edema at 6 patients with a tumor $\leq 4 \mathrm{~cm}$, at 53 of them there was an edema. The edema seen rate was $90 \%$. The average survival was $19.98 \pm 8.0$ (95\% CI: 4.30-35.66) months, 1 and 3 years survival rates were $40 \%$ and $40 \%$ respectively at patients with a $\leq 4 \mathrm{~cm}$ tumor without an edema. The average survival was $14.77 \pm 2.42$ (95\% CI: 10.02-19.51) months, 1 and 3 years survival rates were $35.5 \%$ and $10.2 \%$ respectively at patients with a $\leq 4 \mathrm{~cm}$ tumor and an edema. There was no statistical difference between two groups $(\mathrm{p}=0.426)$. While there was no edema at 9 patients with a tumor $>4 \mathrm{~cm}$, at 33 of them there was an edema. The edema seen rate was $79 \%$. The average survival was $14.12 \pm 4.05$ (95\% CI: 6.16-22.08) months, 1 and 3 years survival rates were $55.6 \%$ and $0 \%$ respectively at patients with a $>4 \mathrm{~cm}$ tumor without an edema. The average survival was $8.71 \pm 1.04$ (95\% CI: 6.65-10.76) months, 1 and 3 years survival rates were $34.3 \%$ and $0 \%$ respectively at patients with a $>4 \mathrm{~cm}$ tumor and an edema. There was no statistical difference 
between two groups ( $\mathrm{p}=0.141)$. If all groups compared with each other, there couldn't be found a statistical difference $(\mathrm{p}=0.259)$.

If it was evaluated for surgical operation; because 23 $(23 \%)$ of the patients were accepted as medical inoperable, the diagnosises were made radiologically. While at 6 of these patients there was no edema, at 17 of them there was an edema. The edema seen rate was $74 \%$. The average survival was $12.10 \pm 4.91$ (95\% CI: $2.47-21.73$ ) months, 1 and 3 years survival rates were $33.3 \%$ and $0 \%$ respectively at the group with no edema. The average survival was $8.55 \pm 2.21$ (95\% CI: $4.21-12.89$ ) months, 1 and 3 years survival rates were $26.8 \%$ and $0 \%$ respectively at the group with an edema. There was no statistical difference between two groups $(\mathrm{p}=0.571)$. While at 6 of the patients who were applied biopsy and subtotal excision there was no edema, at 38 of them there was an edema. The edema seen rate was $86 \%$. The average survival was $12.60 \pm 5.98$ (95\% CI: 0.86-24.34) months, 1 and 3 years survival rates were $40 \%$ and $20 \%$ respectively at the group with no edema. The average survival was $11.61 \pm 1.62$ (95\% CI: 8.42-14.80) months, 1 and 3 years survival rates were $34.5 \%$ and $0 \%$ respectively at the group with an edema. There was no statistical difference between two groups $(\mathrm{p}=0.588)$. While at 4 of the patients who were applied total excision there was no edema, at 30 of them there was an edema. The edema seen rate was $88 \%$. The average survival was $31.93 \pm 6.83$ (95\% CI: 18.53-45.33) months, 1 and 3 years survival rates were $100 \%$ and $50 \%$ respectively at the group with no edema. The average survival was $18.18 \pm 3.88$ (95\% CI: 10.57-25.80) months, 1 and 3 years survival rates were $39.4 \%$ and $24.3 \%$ respectively at the group with an edema. There was no statistical difference between two groups $(\mathrm{p}=0.141)$. If all groups compared with each other, there couldn't be found a statistical difference $(\mathrm{p}=0.167)$. Table 1 demonstrates patient characteristics and results of log-rank univariate analysis for overall survival.

\section{Discussion}

The GBM is most common primary malign brain tumor. The first priority treatment at this disease is the maximal safe resection. The relationship between surgical resection's width and survival was shown in previous surgical series. Because the local recurrences inevitable, it is breeding a need for an adjuvant treatment. The first RT studies related with the adjuvant treatment is the wide area (whole brain) irradiations in the literature. It is shown the RT's positive affect to the survival at the comparison of the patients who have whole brain RT after surgical treatment and the patients who didn't have any adjuvant therapy. But, because of the brain's tolerance dosage, lower dosages were used at these wide area irradiations. Later, at the otopsy series, by reason of the disease's recurrences' $90 \%$ were being at the first $2 \mathrm{~cm}$ and were being shown the tumor cells' existance in the peritumoral edema tissue, it was started to apply higher dosages to more limited areas and it was determined that there was an advantage on survival with these applications.[12] However it was tried many agents for a systemic treatment, the breaking point at this field which is determining nowadays' standarts was held by Stupp and his colleagues[5] in 2005 by the application of $75 \mathrm{mg} / \mathrm{m}^{2} \mathrm{TMZ}$ simultaneously with 60 Gy RT. The most evident response was seen at the patients who had MGMT mutation. Today, even though many tests were made with new technologies and new devices like dosage escalation and/or additional dosage stereotactic boost, there is no randomized evidence that shows efficacy of over 60 Gy dosages yet.

It was come to a certain point at systemic treatment as well as local treatment on GBM and it couldn't be gone beyond Stupp's study.[6] It is similar for prognostic factors. The RPA classification is still remains the feature of being the most used and the most valid classification. The age, performance state, resection width, duration of symptoms, neurologic-functional mental state and tumor's cross over status to the other lobe are the best known prognostic factors. The publications about the peritumoral edema's being a prognostic factor question that's our study's main goal as well, are controversial. Although it is already known that there are tumoral cells surrounding the tumor's edema and included to the RT literature, being inevitable of the local recurrences directed us to search this subject.

The necrosis MR is one of the pathognomonic factors for GBM, too. Also, the peritumoral edema's being wide situation at these tumors is a frequent situation at diagnosis phase or at the patients not having stereoids. It is being thought that the widespread edema at the diagnosis phase is related with the tumor's biological behaviour. $\mathrm{Wu}$ and his colleagues reported that at the retrospective analysis which they examined 109 patients' with malign glioma preoperative MR images, the edema and necrosis were negative prognostic indicators for overall survival. Also, they suggested these tumor cells in the peritumoral edema area could be related to the unresponsiveness to the treatment. It was indicated that this peritumoral edema's effect was controversial in the Liu and his colleagues' study.[13] Even it was stated 
Table 1 Patient characteristics and results of log-rank univariate analysis for overall survival.

\begin{tabular}{|c|c|c|c|c|c|c|c|}
\hline & Peritumoral edema & $\mathbf{n}$ & Overall survival & 1 year survival (\%) & 3 years survival (\%) & & $\mathbf{p}$ \\
\hline \multirow[t]{3}{*}{ General } & No & 15 & $16.67 \pm 3.99$ & 50 & 16.7 & & \multirow{3}{*}{0.297} \\
\hline & & & (95\% Cl: 8.85-24.49) & & & & \\
\hline & Yes & 86 & $\begin{array}{c}13.74 \pm 1.95 \\
(95 \% \mathrm{Cl}: 9.91-17.58)\end{array}$ & 35.6 & 8.5 & & \\
\hline \multicolumn{8}{|l|}{ Sex } \\
\hline \multirow[t]{4}{*}{ Female } & No & 5 & $21.40 \pm 7.32$ & 50 & 25 & \multirow{4}{*}{0.145} & \multirow{8}{*}{0.619} \\
\hline & & & (95\% Cl: 7.04-35.75) & & & & \\
\hline & Yes & 34 & $11.44 \pm 1.91$ & 33.8 & - & & \\
\hline & & & (95\% Cl: 7.69-15.20) & & & & \\
\hline \multirow[t]{4}{*}{ Male } & No & 10 & $13.79 \pm 4.18$ & 50 & 12.5 & \multirow{4}{*}{0.706} & \\
\hline & & & (95\% Cl: 5.58-22.0) & & & & \\
\hline & Yes & 52 & $14.42 \pm 2.64$ & 34 & 10.4 & & \\
\hline & & & (95\% Cl: 9.23-19.61) & & & & \\
\hline \multicolumn{8}{|l|}{ Age } \\
\hline \multirow[t]{4}{*}{$<50$} & No & 4 & $26.99 \pm 4.63$ & 75 & 25 & \multirow{4}{*}{0.800} & \multirow{8}{*}{0.034} \\
\hline & & & (95\% Cl: 17.91-36.07) & & & & \\
\hline & Yes & 11 & $23.91 \pm 4.10$ & 70.7 & - & & \\
\hline & & & (95\% Cl: 15.87-31.96) & & & & \\
\hline \multirow[t]{4}{*}{$\geq 50$} & No & 11 & $12.15 \pm 4.49$ & 30 & 15 & \multirow{4}{*}{0.916} & \\
\hline & & & (95\% Cl: 3.33-20.96) & & & & \\
\hline & Yes & 75 & $11.04 \pm 1.53$ & 30.1 & 4.3 & & \\
\hline & & & (95\% Cl: 8.02-14.06) & & & & \\
\hline \multicolumn{8}{|l|}{ Tumor size } \\
\hline \multirow[t]{4}{*}{$\leq 4 \mathrm{~cm}$} & No & 6 & $19.98 \pm 8.00$ & 40 & 40 & \multirow{4}{*}{0.426} & \multirow{8}{*}{0.259} \\
\hline & & & (95\% Cl: 4.30-35.66) & & & & \\
\hline & Yes & 53 & $14.77 \pm 2.42$ & 35.5 & 10.2 & & \\
\hline & & & (95\% Cl: 10.02-19.51) & & & & \\
\hline \multirow[t]{4}{*}{$>4 \mathrm{~cm}$} & No & 9 & $14.12 \pm 4.05$ & 55.6 & - & \multirow{4}{*}{0.141} & \\
\hline & & & (95\% Cl: 6.16-22.08) & & & & \\
\hline & Yes & 33 & $8.71 \pm 1.04$ & 34.3 & - & & \\
\hline & & & (95\% Cl: 6.65-10.76) & & & & \\
\hline Treatment & & & & & & & \\
\hline Radiological & No & 6 & $12.10 \pm 4.91$ & 33.3 & - & & \\
\hline & & & (95\% Cl: 2.47-21.73) & & & 0.571 & \\
\hline & Yes & 17 & $8.55 \pm 2.21$ & 26.8 & - & ו ו & \\
\hline & & & (95\% Cl: 4.21-12.89) & & & & \\
\hline Biopsy-subtotal & No & 6 & $12.60 \pm 5.98$ & 40 & 20 & & \\
\hline & & & (95\% Cl: 0.86-24.34) & & & 0.588 & 0.167 \\
\hline & Yes & 38 & $11.61 \pm 1.62$ & 34.5 & - & & \\
\hline & & & (95\% Cl: 8.42-14.80) & & & & \\
\hline Total & No & 4 & $31.93 \pm 6.83$ & 100 & 50 & & \\
\hline & & & (95\% Cl: 18.53-45.33) & & & 0.141 & \\
\hline & Yes & 30 & $\begin{array}{c}18.18 \pm 3.88 \\
(95 \% \text { Cl: } 10.57-25.80)\end{array}$ & 39.4 & 24.3 & & \\
\hline
\end{tabular}

that the radiological differences of the malign gliomas including histological differences could be causing this debate. The sharpness of the boundaries of the edema surrounding the mass was also examined but it lost the meaningfulness in the multivariant analysis.
Wu CX and his colleagues[14] study, the enhancement extent was associated with the OS of the patients with malignant glioma on univariate analysis, while it failed to retain its significance on multivariate analysis. Schoenegger $\mathrm{K}$ et al.[15] results confirm that peritu- 
moral edema on preoperative MRI is an independent prognostic factor in addition to postoperative Karnofsky performance score (KPS), age, and type of tumor resection. Patients with major edema had significant shorter overall survival compared to patients with minor edema.

The results of our study are inconclusive; the available evidence does not certainly support or rule out an association between pre-operative peritumoral edema and overall survival $(\mathrm{p}=0.297)$. However, the patients under 50 years with no edema had significant long overall survival compared to patients 50 years old and over with edema $(\mathrm{p}=0.034)$.

For a conclusion, the edema's prognostic value couldn't be determined on the survival in the retrospective analysis of our homogeneous group formed from isolated GBM patients. There is a need for randomized studies with higher patient numbers for researching this subject.

\section{Disclosure Statement}

The authors declare no conflicts of interest.

\section{References}

1. Ostrom QT, Gittleman H, Farah P, Ondracek A, Chen Y, Wolinsky Y, et al. CBTRUS statistical report: Primary brain and central nervous system tumors diagnosed in the United States in 2006-2010. Neuro Oncol 2013;15 Suppl 2:ii1-56. Crossre

2. Rosell R, de Las Peñas R, Balaña C, Santarpia M, Salazar F, de Aguirre I, et al. Translational research in glioblastoma multiforme: molecular criteria for patient selection. Future Oncol 2008;4(2):219-28. Crossre

3. Ammirati M, Vick N, Liao YL, Ciric I, Mikhael M. Effect of the extent of surgical resection on survival and quality of life in patients with supratentorial glioblastomas and anaplastic astrocytomas. Neurosurgery 1987;21(2):201-6. Erossree

4. Fine HA. The basis for current treatment recommendations for malignant gliomas. J Neurooncol 1994;20(2):111-20. Crossre

5. Stupp R, Mason WP, van den Bent MJ, Weller M, Fisher B, Taphoorn MJ, et al. Radiotherapy plus concomitant and adjuvant temozolomide for glioblastoma. $\mathrm{N}$
Engl J Med 2005;352(10):987-96. Crossere

6. Stupp R, Hegi ME, Mason WP, van den Bent MJ, Taphoorn MJ, Janzer RC, et al. Effects of radiotherapy with concomitant and adjuvant temozolomide versus radiotherapy alone on survival in glioblastoma in a randomised phase III study: 5-year analysis of the EORTC-NCIC trial. Lancet Oncol 2009;10(5):459-66.

7. Chang $\mathrm{CH}$, Horton J, Schoenfeld D, Salazer O, PerezTamayo R, Kramer S, et al. Comparison of postoperative radiotherapy and combined postoperative radiotherapy and chemotherapy in the multidisciplinary management of malignant gliomas. A joint Radiation Therapy Oncology Group and Eastern Cooperative Oncology Group study. Cancer 1983;52(6):997-1007.

8. Curran WJ Jr, Scott CB, Horton J, Nelson JS, Weinstein AS, Fischbach AJ, et al. Recursive partitioning analysis of prognostic factors in three Radiation Therapy Oncology Group malignant glioma trials. J Natl Cancer Inst 1993;85(9):704-10. Crossree

9. Burger PC, Green SB. Patient age, histologic features, and length of survival in patients with glioblastoma multiforme. Cancer 1987;59(9):1617-25. Crossree

10. Donato V, Papaleo A, Castrichino A, Banelli E, Giangaspero F, Salvati M, et al. Prognostic implication of clinical and pathologic features in patients with glioblastoma multiforme treated with concomitant radiation plus temozolomide. Tumori 2007;93(3):248-56.

11. Abacioğlu U, Çetin İ, Akgün Z, Şengöz M. Treatment results and prognostic factors for adult patients with diagnosis of glioblastoma multiforme after radiotherapy. Türk Onkoloji Dergisi 2004;19(3):112-8.

12. Silbergeld DL, Rostomily RC, Alvord EC Jr. The cause of death in patients with glioblastoma is multifactorial: clinical factors and autopsy findings in 117 cases of supratentorial glioblastoma in adults. J Neurooncol 1991;10(2):179-85. Crossree

13. Liu SY, Mei WZ, Lin ZX. Pre-operative peritumoral edema and survival rate in glioblastoma multiforme. Onkologie 2013;36(11):679-84 Crossre

14. Wu CX, Lin GS, Lin ZX, Zhang JD, Chen L, Liu SY, et al. Peritumoral edema on magnetic resonance imaging predicts a poor clinical outcome in malignant glioma. Oncol Lett 2015;10(5):2769-76. Crossre

15. Schoenegger K, Oberndorfer S, Wuschitz B, Struhal W, Hainfellner J, Prayer D, et al. Peritumoral edema on MRI at initial diagnosis: an independent prognostic factor for glioblastoma? Eur J Neurol 2009;16(7):874-8. 